\title{
EVALUATION OF HAND HYGIENE: IS UNIVERSITY MEDICAL EDUCATION EFFECTIVE IN PREVENTION OF HOSPITAL-ACQUIRED INFECTIONS?
}

\author{
Simona Kelčíková1, Lucia Mazúchová1, Nora Malinovská2, Jana Kopincová3, Ingrid Tonhajzerová3 \\ ${ }^{1}$ Department of Midwifery, Jessenius Faculty of Medicine in Martin, Comenius University in Bratislava, Martin, Slovak Republic \\ 2Department of Foreign Languages, Jessenius Faculty of Medicine in Martin, Comenius University in Bratislava, Martin, Slovak Republic \\ ${ }^{3}$ Department of Physiology, Jessenius Faculty of Medicine in Martin, Comenius University in Bratislava, Martin, Slovak Republic
}

\begin{abstract}
SUMMARY
Objective: Hand hygiene $(\mathrm{HH})$ compliance is associated with effective prevention of health care-associated infections (HAl), the topic being very important due to current COVID-19 pandemic. There is a growing debate about the role of educational institutions in the low HH compliance of health workers. This study aimed to assess $\mathrm{HH}$ knowledge, self-assessment and attitudes of medical students in relation to provided educational background.

Methods: A cross-sectional survey (mixed methods-approach) combined with the curriculum analysis and questionnaires. Quantitative method: a questionnaire of knowledge of $\mathrm{HH}$ issues (QK), and a questionnaire of self-assessment and attitudes (SAQ) towards $\mathrm{HH}$. Qualitative method focused on an analysis of content of the curriculum documents.

Results: 250 (KQ) and 238 (SAQ) questionnaires were analysed from students of general medicine ( $n=262$; average age 22.5 years). Belowaverage knowledge of $\mathrm{HH}$ and a high self-assessment of knowledge and compliance with $\mathrm{HH}$ was reported by $72.2 \%$ and $76.0 \%$ of students, respectively. Significant differences in knowledge and self-assessment of $\mathrm{HH}$ were found among study years and gender. The content analysis has revealed gaps in $\mathrm{HH}$-related information in general medicine educational programme.

Conclusions: It is highly expected that there might be some association between low HH knowledge level, false self-assessment and educational programme in medical students.
\end{abstract}

Key words: hand hygiene, hospital-acquired infections, knowledge, self-assessment, medical education, content analysis

Address for correspondence: L. Mazúchová, Department of Midwifery, Jessenius Faculty of Medicine in Martin, Comenius University in Bratislava, Malá Hora 5, 03601 Martin, Slovak Republic. E-mail: lucia.mazuchova@uniba.sk

https://doi.org/10.21101/cejph.a6501

\section{INTRODUCTION}

Compliance with hand hygiene $(\mathrm{HH})$ is an essential tool for the prevention of health care-associated infections (HAI) which occur and develop in healthcare facilities, especially in hospitals (1-3). The incidence ranges from $6 \%$ to $10 \%$ in the developed world (1). In relation to the current COVID-19 pandemic situation, $\mathrm{HH}$ represents highly topical and crucial issue.

Despite the long history of HH, since the time of Semmelweis, and its clinical importance, a number of studies have reported very low compliance (usually below 50\%) with the fundamental $\mathrm{HH}$ standards among healthcare workers (HCWs) in hospital settings, though $\mathrm{HH}$ compliance is fairly simple $(1,4)$.

In clinical practice, $\mathrm{HH}$ compliance is a complex problem and system modifications across all healthcare facilities and organizations are needed to improve $\mathrm{HH}$ performance $(5,6)$. There are numerous factors affecting $\mathrm{HH}$ compliance, with appropriate knowledge and individual attitudes of HCWs at the head (7-10). Thus, research is usually focused on the identification of the main factors contributing to low compliance among HCWs (9), considering $\mathrm{HH}$ compliance is a complex behavioural phenomenon with a variety of possible explanations and not only a matter of simple mechanical tasks (7). Many reasons for unwillingness of HCWs to comply with HH standards were identified, some of them cannot be changed, but others could be effectively modified (11).

The level of $\mathrm{HH}$ compliance among HCWs is crucial for medical students in hospitals as the students self-image regarding $\mathrm{HH}$ compliance often reflects the experienced standards $(3,7)$.

The aim of the study was to assess HH knowledge, self-assessment, attitudes and compliance with $\mathrm{HH}$ in medical students, and thus help to minimize the risk of HAIs. Simultaneously, a content analysis of the curriculum documents in general medicine education was used to reveal the real situation in $\mathrm{HH}$ education.

\section{MATERIALS AND METHODS}

\section{Study Design}

The mixed method approach involving a cross-sectional survey combined with the curriculum analysis and questionnaires was used: the questionnaire on Knowledge of $\mathrm{HH}$ compliance (KQ) 
and questionnaire on Self-assessment of $\mathrm{HH}$ compliance and on Attitudes to $\mathrm{HH}$ (SAQ); content analysis of curriculum documents in the basic medical education.

\section{Data Collection and Sample}

The study was conducted at Jessenius Faculty of Medicine in Martin, Comenius University in Bratislava, Slovak Republic. Data collection took place from 2018 to 2019.

The analysed group consisted of 262 medical students of the 2 nd to 6 th study year with average age of 22.46 (SD 1.5). A total of 400 questionnaires were distributed (personally) with the response rate of $65.5 \%$. We analysed 250 Knowledge questionnaires (KQs) (12 questionnaires were excluded) and 238 Self-assessment and Attitudes questionnaires (SAQs) (24 questionnaires were excluded). The reliability of questionnaires determined by the Cronbach's alpha ( 0.72 for KQ and 0.80 for SAQ). The group characteristic is given in Table 1.

\section{Ethical Approval}

The research was conducted in compliance with the Slovak national legislation and the Helsinki Declaration (2013). The study was approved by the Comenius University Ethics Committee (Number EC 31/2019). All participants received full information about the nature and goals of the research, as well as about the details of their involvement in the study. The data collection was anonymous, and all participants expressed their will to be included in the study by signing informed consent.

\section{Questionnaires}

The modified questionnaires were used to collect other relevant data for the research objective.

Knowledge of HH compliance questionnaire (KQ) was designed specifically for the purposes of our study. The questionnaire consisted of 47 questions intended to measure the HH knowledge level among medical students, including hand disinfection, hand washing techniques and the spread of HAIs. Research and international documents were reviewed to identify the basic knowledge level and habits related to the $\mathrm{HH}$ issue according to the international standards $(1,12)$. The following four subscales of the questionnaire were designed:

Table 1. Overview of participating students

\begin{tabular}{|l|c|c|}
\hline Questionnaire & Knowledge (QK) & $\begin{array}{c}\text { Self-assessment and } \\
\text { attitudes (SAQ) }\end{array}$ \\
\hline Year/gender & $\mathrm{n} \mathrm{( \% )}$ & $\mathrm{n}(\%)$ \\
\hline 2nd year & $57(22.8)$ & $54(22.6)$ \\
\hline 3rd year & $31(12.4)$ & $29(12.2)$ \\
\hline 4th year & $65(26.0)$ & $63(26.5)$ \\
\hline 5th year & $86(34.4)$ & $81(34.0)$ \\
\hline 6th year & $11(4.4)$ & $11(4.6)$ \\
\hline Females & $194(77.6)$ & $190(80.0)$ \\
\hline Males & $56(22.4)$ & $48(20.2)$ \\
\hline Total & $250(100.0)$ & $238(100.0)$ \\
\hline
\end{tabular}

Hand hygiene $(H H)$ consisted of 12 items that covered the factors positively influencing the performance of $\mathrm{HH}$ in clinical practice, the insufficient compliance with $\mathrm{HH}$ as a cause of HAIs and the knowledge of the hand decontamination procedure as one of basic tools for HAI prevention.

Disinfectants (D) consisted of 14 items that covered the issues of antimicrobial activity of alcohol-based disinfectants, proper procedures of rubbing the alcohol agent into the skin, and the use of antiseptic wet towels as an alternative to hand disinfection.

Hand preparation (HP) consisted of 11 items that covered the topics related to nail hygiene, including wearing jewellery/ watches and the use of protective gloves.

Hand washing techniques (HWT) consisted of 10 items; this subscale included the questions focused on the proper hand washing techniques, and hand disinfection procedures.

The total score of the questionnaire was 260 points, and the level of the HH standards knowledge was evaluated as follows: A - excellent knowledge (100\% to 96\%); B - very good knowledge ( $95 \%$ to $89 \%$ ); C - good knowledge ( $88 \%$ to $78 \%$ ); D - satisfactory knowledge ( $77 \%$ to $68 \%)$; E - sufficient knowledge meeting only the minimum criteria (67\% to $60 \%)$; and FX - insufficient knowledge (59\% and less). The questionnaire reliability was established using the internal consistency indicator (Cronbach's alpha was 0.72).

Self-assessment and Attitudes questionnaire (SAQ) - the modified questionnaire according to Pittet et al. (7) and Cole (9) was used. This was developed following the guidelines for the social-cognitive theory applied to a health-related behaviour, and on the basis of the theory of planned behaviour (14). The concept of the questionnaire aimed to evaluate the cognitive factors associated with self-assessment of the compliance with $\mathrm{HH}$ and attitudes to HH. Questions (Q) 1, 2 and 4-6 focused on the rational features of self-assessment, and Q3a, 3b, 3c, 7a, 7b, and 7c focused on perception of $\mathrm{HH}$ as a useful tool in the specific clinical situations. The answers were evaluated using the 7-point Likert scale. The lowest score values (grade 1 or 2 on a scale) in the responses to Q1, 2, and 4-6 presented the low level of self-assessment, and the highest values (grade 6 or 7) presented the high degree of self-assessment. In contrast, for Q3a, 3b, 3c, 7a, 7b, and 7c the highest score values (grade 6 or 7) in the responses presented the positive attitudes towards $\mathrm{HH}$ and the lowest values (grade 1 or 2) presented an unconcerned attitude and perception of $\mathrm{HH}$ as being unnecessary, in detail considering the non-compliance with $\mathrm{HH}$ being the minimal risk of infection. Motivation to improve $\mathrm{HH}$ (Q8) was evaluated using the 3-point scale. The questionnaire reliability was determined by the Cronbach's alpha with the value of 0.80 . The list of the questions is shown in Table 5 .

\section{Curriculum Analysis}

A content analysis of the curriculum documents in the basic medicine education was used to investigate occurrence of information related to $\mathrm{HH}$ in both mandatory and optional subjects. The basic set of documents used for the content analysis consisted of the information subject sheets (ISSs) containing a comprehensive description of topics covered in each subject in the current academic year of medical education. Three key terms relevant to the research objective were selected as the basic analytical units of the text: "hand hygiene"; "disinfection of hands in relation to 
the clinical activity"; and "procedure of rubbing the disinfectant into hands". In accordance with the standard procedure in the content analysis, data from both the qualitative and the quantitative aspects were examined.

Quantitative method in curriculum analysis was performed following the listed procedures: search for dichotomy (presence or absence) of analysed units (an indicator that expressed the number of ISSs containing or not containing the analysed units); and search for frequency of occurrence (how many times is the unit "hand hygiene"; "disinfection of hands in relation to the clinical activity"; or "procedure of rubbing the disinfectant into hand" present in ISS).

Qualitative method included the assessment of contingency (an indicator of the interrelationship between the analysed units and other key issues relevant to the research objective). During this process, ISSs were browsed for the occurrence of similar key concepts related to "hand hygiene"; "disinfection of hands" and the "procedure of rubbing the disinfectant into hands".

\section{Data Analysis}

Prior to further analysis, the Kolmogorov-Smirnov normality test was used to test the normal distribution of our data. As the normal distribution was not confirmed, the non-parametric statistical analyses were used. The response score across the study years and gender was compared using the Kruskal-Wallis test and the Mann-Whitney test, respectively. The $p$-value of $<0.05$ was considered statistically significant. Data are expressed as mean and standard deviation (SD).

\section{RESULTS}

Level of Knowledge Based on Questionnaire Responses

More than half of students $(56.8 \%)$ met only the minimum criteria (E-level) according to the classification applied in the study; and 32\% showed insufficient knowledge (FX-level). The average $\mathrm{HH}$ knowledge level among the students regarding the year of study is shown in Table 2.

The lowest HH knowledge level was found in the students of the final year with mean score of $63 \%$ (161 points of total 260). Kruskal-Wallis ANOVA test revealed significant differences when comparing the knowledge level among the students across the study years $(\mathrm{p}=0.027)$.

The highest knowledge level was recorded among the $3 \mathrm{rd}$ and 2nd-year students (Table 2). The results in the specific subscales of KQ showed the highest knowledge level in the HP subscale, whereas the lowest knowledge level was found in the HWT subscale (Table 3).

The students showed an unacceptable score in the subscale of "Hand washing techniques" and "Disinfectants" in the questions related to effects and properties of disinfectants; antimicrobial activity of alcohol-based disinfectants; time and the way how to rub alcohol-based disinfectant into hands; recommended disinfectant time interval; and suitability of using antiseptic wet wipes as an alternative to hand disinfection (Table 3).

Significant differences were revealed in the HP subscale between particular year-classes $(p=0.01)$

Table 2. Results of knowledge level according to $H H$ knowledge questionnaire in each study year $(N=250)$

\begin{tabular}{|l|c|c|c|c|c|c|}
\hline \multirow{2}{*}{ Study year } & \multicolumn{2}{|c|}{$\begin{array}{c}\text { Test score } \\
\text { (\% of 260 points) }\end{array}$} & \multicolumn{4}{|c|}{$\begin{array}{c}\text { Evaluation score } \\
\text { (\% of 250 students) }\end{array}$} \\
\cline { 2 - 8 } & Mean & SD & A-C & D & E & FX \\
\hline 2nd year $(n=57)$ & 65.4 & 6.1 & 0.0 & 8.7 & 61.5 & 29.8 \\
\hline 3rd year $(n=31)$ & 66.0 & 4.9 & 0.0 & 9.7 & 51.6 & 38.7 \\
\hline 4th year $(n=65)$ & 64.4 & 6.1 & 0.0 & 13.9 & 56.9 & 29.2 \\
\hline 5th year $(n=86)$ & 63.8 & 4.9 & 0.0 & 10.5 & 58.1 & 31.4 \\
\hline 6th year $(n=11)$ & 62.8 & 5.5 & 0.0 & 18.2 & 36.4 & 45.4 \\
\hline Total & 64.5 & 5.5 & 0.0 & 11.2 & 56.8 & 32.0 \\
\hline
\end{tabular}

A - excellent knowledge; B - very good knowledge; C - good knowledge; D - satisfactory knowledge; $\mathrm{E}$ - sufficient knowledge; FX - insufficient knowledge; SD - standard deviation

Table 3. Results of knowledge level according to HH knowledge questionnaire in specific subscales of $H H(N=250)$

\begin{tabular}{|c|c|c|c|c|c|c|c|}
\hline Study year & $\begin{array}{c}\text { 2nd year } \\
(n=57)\end{array}$ & $\begin{array}{c}\text { 3rd year } \\
(n=31)\end{array}$ & $\begin{array}{c}\text { 4th year } \\
(n=65)\end{array}$ & $\begin{array}{c}\text { 5th year } \\
(n=86)\end{array}$ & $\begin{array}{c}\text { 6th year } \\
(n=11)\end{array}$ & Total & \multirow{2}{*}{$\begin{array}{c}\mathrm{p} \text {-value } \\
\mathrm{K}-\mathrm{W}\end{array}$} \\
\hline Subscale & \multicolumn{6}{|c|}{ Mean $\%$ of total section points (SD) } & \\
\hline Hand hygiene & $68.0(7.1)$ & $71.0(8.9)$ & $70.1(8.4)$ & $68.6(7.6)$ & $69.6(9.2)$ & $69.2(8.0)$ & 0.293 \\
\hline Disinfectants & $58.9(8.1)$ & $59.8(8.2)$ & $57.9(7.8)$ & $59.2(7.2)$ & $62.6(9.1)$ & $59.0(7.8)$ & 0.437 \\
\hline Hand preparation & $78.1(13.6)$ & $76.0(16.1)$ & $76.2(13.0)$ & $73.6(12.8)$ & $64.2(16.5)$ & $75.2(13.8)$ & 0.010 \\
\hline Hand washing techniques & $57.9(11.4)$ & $56.3(12.0)$ & $53.6(9.4)$ & $53.2(10.0)$ & $53.1(10.2)$ & $54.7(10.5)$ & 0.262 \\
\hline Total & $65.4(6.1)$ & $66.0(4.9)$ & $64.4(6.1)$ & $63.8(4.9)$ & $62.8(5.5)$ & $64.5(5.5)$ & 0.027 \\
\hline
\end{tabular}

SD - standard deviation; K-W - Kruskal-Wallis test 
Females showed better HH knowledge than males. However, both genders showed an unsatisfactory level of knowledge regarding $\mathrm{HH}$, which was proved to be significant $(\mathrm{p}=0.028)$. Overall, the female medical students achieved a higher average knowledge score than the male medical students in all subscales of the questionnaire with "Disinfectants" being significant $(\mathrm{p}=0.011)$.

\section{Self-assessment Based on Questionnaire Responses}

Medical students had high degree of self-assessment in $\mathrm{HH}$ (Table 4, Q 1, 2, 4-6).

While providing patient care, $72.2 \%$ of medical students consider themselves adhering to the recommended $\mathrm{HH}$ guidelines (the percentages refer to responses in grades 5 to 7; Q1). Recommended indications for correct $\mathrm{HH}$ were thought to be known to $76.0 \%$ of respondents - answers to the appropriate question (Q2) reached the highest score 5.37. In contrast, only 53.3\% of respondents thought that their fellow students respect the $\mathrm{HH}$ guidelines (Q4). Among medical students, $62.5 \%$ of respondents considered their HH behaviour an exemplary for their colleagues, while just $5.5 \%$ reflected their $\mathrm{HH}$ behaviour non-exemplary at all (Q5); 36.8\% of medicine students thought that compliance with $\mathrm{HH}$ is not difficult, nonetheless, $16.0 \%$ found $\mathrm{HH}$ compliance always difficult (Q6).

In response to Q8, almost half of respondents $(67.5 \%)$ declared their motivation and perception of the need to improve their compliance with $\mathrm{HH}$, while only $1.7 \%$ of respondents saw no need to improve their compliance with HH (Table 4).

\section{Attitudes Based on Questionnaire Responses}

In identifying attitudes and perceptions of $\mathrm{HH}$ under specific clinical conditions, medical students overall demonstrated a positive attitude (Table 4, Q3a, 3b, 3c, 7a, 7b, 7c). The vast majority of the students perceived $\mathrm{HH}$ as a useful tool to prevent infection transmission (the percentages refer to responses in grades 5 to 7): 88.2\% in Q3a; 95.9\% in Q3b; and 69.3\% in Q3c. Additionally, a majority of medical students consider non-adherence to $\mathrm{HH}$ a significant risk of infection transmission: $89.5 \%$ in Q7a. The lowest mean value of the score 4.74 in response to Q7c suggests a problem with the use of gloves. The responses to Q7c also show the greatest variability.

In responses to the $\mathrm{HH}$ self-assessment-related questions, the 4th-year medical students manifested higher self-esteem than the students from the other study years. The 4th-year students were also more critical in relation to their $\mathrm{HH}$ behaviour, reaching the lowest mean value of the score $(3.67 \pm 1.40)$ in responses to all questions (Q1, 2, 4, 5, 6). However, their evaluation of the compliance with $\mathrm{HH}$ according to the recommended guidelines $(\mathrm{Q} 1,2)$ did not differ from the others. The statistically significant results were confirmed in the questions related to the compliance with HH under specific clinical conditions (Table 4, Q4, 5, 6,).

In responses to the $\mathrm{HH}$ attitude-related questions (Q3a, 3b, $3 \mathrm{c}, 7 \mathrm{a}, 7 \mathrm{~b}, 7 \mathrm{c}$ ), the 3rd-year students more than the others consider $\mathrm{HH}$ a significant factor and useful tool for the prevention of the infection spread in the healthcare units $(7.00 \pm 0.00)$. The statistically significant results were confirmed in the questions related to perception towards $\mathrm{HH}$ under specific clinical conditions (Table 5, Q3).

Table 4. Absolute and relative frequencies of self-assessment, attitudes, beliefs and perception related to $\mathrm{HH}$

\begin{tabular}{|l|c|c|c|c|c|c|c|c|c|}
\hline \multirow{2}{*}{ Questions (score specification) } & 1 & 2 & 3 & 4 & 5 & 6 & 7 & Absolute frequency (relative frequency in \%) \\
\cline { 2 - 9 } & \multicolumn{7}{|c|}{ Mean (SD) } \\
\hline Self-assessment of compliance with HH \\
\hline Q1 (never 1 - always 7) & $3(1.3)$ & $4(1.7)$ & $23(9.7)$ & $36(15.1)$ & $84(35.3)$ & $61(25.6)$ & $27(11.3)$ & $5.04(1.27)$ \\
\hline Q2 (not at all 1 - fully 7) & $2(0.8)$ & $4(1.7)$ & $12(5.0)$ & $39(16.4)$ & $50(21.0)$ & $90(37.8)$ & $41(17.2)$ & $5.37(1.26)$ \\
\hline Q4 (never 1 - always 7) & $3(1.3)$ & $10(4.2)$ & $38(16.0)$ & $60(25.2)$ & $53(22.3)$ & $57(23.9)$ & $17(7.1)$ & $4.63(1.37)$ \\
\hline Q5 (not at all 1 - of course 7) & $8(3.4)$ & $5(2.1)$ & $26(11.0)$ & $51(21.1)$ & $59(24.9)$ & $63(26.6)$ & $26(11.0)$ & $4.86(1.44)$ \\
\hline Q6 (always 1 - never 7) & $17(7.2)$ & $21(8.9)$ & $45(18.6)$ & $68(28.7)$ & $30(12.7)$ & $45(19.0)$ & $12(5.1)$ & $4.08(1.59)$ \\
\hline Q8 (yes - perhaps - no) & $161(67.5)$ & & $73(30.8)$ & & $4(1.7)$ & $1.34(0.51)$ \\
\hline Attitudes to HH or specific situations in which HH may be important & $0(0.0)$ & $0(0.0)$ & $4(1.7)$ & $24(10.1)$ & $20(8.4)$ & $25(10.5)$ & $165(69.3)$ & $6.36(1.10)$ \\
\hline Q3a (useless 1 - useful 7) & $0(0.0)$ & $2(0.8)$ & $2(0.8)$ & $6(2.5)$ & $7(3.0)$ & $16(6.8)$ & $205(86.1)$ & $6.72(0.83)$ \\
\hline Q3b (useless 1 - useful 7) & $5(2.1)$ & $5(2.1)$ & $18(7.6)$ & $45(18.9)$ & $32(13.4)$ & $41(17.2)$ & $92(38.7)$ & $5.46(1.59)$ \\
\hline Q3c (useless 1 - useful 7) & $3(1.3)$ & $3(1.3)$ & $6(2.5)$ & $13(5.5)$ & $30(12.7)$ & $47(19.8)$ & $136(57.0)$ & $6.14(1.28)$ \\
\hline Q7a (no risk 1 - significant risk 7) & $1(0.4)$ & $0(0.0)$ & $4(1.7)$ & $6(2.5)$ & $11(4.6)$ & $36(15.2)$ & $180(75.5)$ & $6.59(0.91)$ \\
\hline Q7b (no risk 1 - significant risk 7) & $6(2.5)$ & $15(6.3)$ & $23(9.7)$ & $64(27.0)$ & $51(21.5)$ & $40(16.5)$ & $39(16.5)$ & $4.74(1.55)$ \\
\hline Q7c (no risk 1 - significant risk 7)
\end{tabular}

Q1 - Do you think that you follow proper $\mathrm{HH}$ in patient care according to the recommended guidelines?; Q2 - Do you know the recommended indications of proper HH?; Q3a - Do you consider HH in the following situation "between treating of dirty/contaminated and clean/sterile wound" to be a useless or useful tool to prevent the spread of infections in healthcare units; Q3b - Do you consider HH in the following situation "after a contact with body fluids" to be a useless or useful tool to prevent the spread of infection in healthcare units?; Q3c - Do you consider HH in the following situation "after removal/taking off gloves" to be a useless or useful tool to prevent the spread of infection in healthcare units?; Q4 - Do your colleagues comply with hand hygiene according to the recommended guidelines?; Q5 - Do you think that your HH behaviour is considered to be exemplary by your colleagues?; Q6 - Is it difficult to adhere to $\mathrm{HH}$ according to the recommended guidelines?; Q7a - Does the non-compliance with $\mathrm{HH}$ in the following situation "treating of dirty/contaminated and clean/sterile wound" present a risk of the spread of infection to a patient?; Q7b - Does the non-compliance with $\mathrm{HH}$ in the following situation "upon contact with body fluids" present a risk of the spread of infection to a patient?; Q7c - Does the non-compliance with HH in the following situation "after removal/taking off gloves" present a risk of the spread of infection to a patient? Q8 - Do you feel that you can improve compliance with hand hygiene? 
In responses to questions focused on self-assessment, the males manifested significantly higher self-esteem than the females; males were more critical to their HH behaviour (Q1, 2, 4, 5, 6). The significant difference was revealed only in the question Q2 and total QS (Table 5, Q2). The male medical students (4.94 \pm 1.44 ) were more critical than the female medical students in the assessment concerning the knowledge of the recommended indications of proper $\mathrm{HH}(5.48 \pm 1.19)$.

When the attitudes of the females and males were compared, the significant difference was revealed in the question Q3a, 3b and total QS (Table 5). The females perceived $\mathrm{HH}$ to be much more significant and useful tool for the prevention of infection transmission in healthcare units between treating of dirty/contaminated and clean/sterile wound (Table 5, Q3a, 6.46+1.03); after a contact with body fluids $(\mathrm{Q} 3 \mathrm{~b}, 6.81+0.69)$ than the males $(\mathrm{p}<0.05)$. This was confirmed by the higher frequency of responses in grades 6 and 7 in the group of the females (Q3a, 3b). Moreover, a greater part of the females considered non-compliance with $\mathrm{HH}$ in all questions $7 \mathrm{a}, 7 \mathrm{~b}$, and $7 \mathrm{c}$ risky for a patient (responses in grades 6 and 7).

The results of the frequency analyses did not show any significant differences in relation to the Q8 (suggestions how to improve compliance with $\mathrm{HH}$ ) either in terms of the study years or in terms of gender. The improvement in compliance with $\mathrm{HH}$ was desired by $67.5 \%$ of medical students (Table 4 ). The potential for improvement was seen by $30.8 \%$ of medical students (Table 4).

A significant discrepancy was found between the positive results of the SAQ in the individual study years (SAQ, sum of percentage in responses 5 to 7: Q1 72.2\%, Q2 76.0\%, Table 4) and a low theoretical knowledge as revealed in the $\mathrm{HH}$ questionnaire (KQ: $64.5 \%$, Table 2). It was the most obvious in the final study years $-58.1 \%$ of 5 th-year students reached $\mathrm{E}$ and $31.4 \%$ reached FX; $38.4 \%$ of 6 th-year students reached $\mathrm{E}$, and $45.4 \%$ reached FX (Table 2).

\section{Curriculum Content Analysis}

The basic set of documents used for the curriculum analysis consisted of 71 ISSs covering all subjects in general medicine study programme from the 2 nd to 6 th year of the study. The first step in the analysis was the ISS selection process which consisted of all relevant information on the HH-related issues. Based on this comprehensive qualitative assessment, 37 ISSs containing the HH-related topics were identified and selected: 32 ISSs of the mandatory practical subjects and 5 ISSs of the mandatory theoretical subjects. However, it is necessary to stress that $\mathrm{HH}$ was only marginally covered in all curricular documents.

The search for the dichotomy (presence or absence) of the distinct phrases (hand hygiene, disinfection of hands, procedure of rubbing the disinfectant into hands) revealed zero frequency in ISSs: these key words were not included in any of the analysed ISSs and thus frequency of occurrence of the basic analytical units could not be assessed.

Search for related terms was more successful: 15 additional HH-related key terms were identified in 3 ISSs of the mandatory practical subjects and 1 ISS of the mandatory theoretical subject. The found terms were the following ones (times of repetition): principles of preoperative care; asepsis, antisepsis, sterilization, disinfection (3); nosocomial infections (2); principles of sanitary compliance and sterile technique; principles of wound management; causes and risk factors of surgical site infections; prevention of surgical site infection (2); preparation of the surgeon; surgical preparation of the operating field; hospital hygiene; sanitary-epidemiological regulations in health facilities; prevention, protection of health in the workplace; process of the disease transmission; principles of infectious diseases control; asepsis and antisepsis in the orthopaedic operating room; preparation of the operating team.

The occurrence of the additional HH-related key terms was identified 7 times in early years of study (2nd and 3rd year) and 12 times in the later years (4th, 5th and 6th year of study).

Table 5. Significance rate of self-assessment and attitudes according to study years and gender $(N=238)$

\begin{tabular}{|c|c|c|c|c|c|c|c|c|c|c|}
\hline Study year & $\begin{array}{c}\begin{array}{c}\text { 2nd year } \\
(n=54)\end{array}\end{array}$ & $\begin{array}{c}\text { 3rd year } \\
(n=29)\end{array}$ & $\begin{array}{c}\text { 4th year } \\
(n=63)\end{array}$ & $\begin{array}{c}\text { 5th year } \\
(n=81)\end{array}$ & $\begin{array}{c}\text { 6th year } \\
(n=11)\end{array}$ & Total & \multirow{2}{*}{$\begin{array}{c}\text { p-value } \\
K \text {-W }\end{array}$} & Females & Males & \multirow{2}{*}{$\begin{array}{c}p \text {-value } \\
M-W\end{array}$} \\
\hline Question & Mean (SD) & Mean (SD) & Mean (SD) & Mean (SD) & Mean (SD) & Mean (SD) & & Mean (SD) & Mean (SD) & \\
\hline Q1 & $5.26(1.15)$ & $5.03(1.80)$ & $4.90(1.16)$ & $5.00(1.22)$ & $5.00(1.10)$ & $5.04(1.27)$ & 0.647 & $5.10(1.15)$ & $4.79(1.64)$ & 0.319 \\
\hline Q2 & $5.57(1.25)$ & $5.21(1.50)$ & $5.49(1.06)$ & $5.21(1.35)$ & $5.36(0.92)$ & $5.37(1.26)$ & 0.554 & $5.48(1.19)$ & $4.94(1.44)$ & 0.016 \\
\hline Q4 & $5.13(1.37)$ & $4.69(1.58)$ & $4.43(1.32)$ & $4.48(1.30)$ & $4.36(1.03)$ & $4.63(1.37)$ & 0.045 & $4.69(1.29)$ & $4.40(1.62)$ & 0.309 \\
\hline Q5 & $5.52(1.16)$ & $4.52(1.57)$ & $4.63(1.47)$ & $4.78(1.44)$ & $4.36(1.29)$ & $4.86(1.44)$ & 0.004 & $4.95(1.37)$ & $4.48(1.64)$ & 0.129 \\
\hline Q6 & $4.13(1.76)$ & $5.34(1.57)$ & $3.67(1.40)$ & $3.96(1.46)$ & $3.73(1.56)$ & $4.08(1.59)$ & $<0.001$ & $4.05(1.58)$ & $4.19(1.63)$ & 0.632 \\
\hline Q8 & $1.33(0.58)$ & $1.45(0.57)$ & $1.30(0.46)$ & $1.35(0.48)$ & $1.27(0.47)$ & $1.34(0.51)$ & 0.748 & $1.31(0.50)$ & $1.46(0.54)$ & 0.065 \\
\hline Q3a & $6.04(1.26)$ & $7.00(0.00)$ & $6.24(1.12)$ & $6.41(1.12)$ & $6.55(0.82)$ & $6.36(1.10)$ & 0.001 & $6.46(1.03)$ & $5.96(1.27)$ & 0.006 \\
\hline Q3b & $6.62(0.92)$ & $7.00(0.00)$ & $6.51(1.20)$ & $6.85(0.39)$ & $6.73(0.90)$ & $6.72(0.83)$ & 0.129 & $6.81(0.69)$ & $6.38(1.18)$ & 0.001 \\
\hline Q3c & $5.41(1.54)$ & $5.69(1.56)$ & $5.33(1.68)$ & $5.44(1.64)$ & $5.91(1.14)$ & $5.46(1.59)$ & 0.762 & $5.50(1.59)$ & $5.29(1.62)$ & 0.400 \\
\hline Q7a & $6.13(1.23)$ & $6.48(1.30)$ & $6.10(1.44)$ & $6.06(1.23)$ & $6.18(0.98)$ & $6.14(1.28)$ & 0.187 & $6.19(1.26)$ & $5.96(1.37)$ & 0.236 \\
\hline Q7b & $6.56(0.82)$ & $6.97(0.19)$ & $6.46(1.03)$ & $6.58(1.02)$ & $6.55(0.69)$ & $6.59(0.91)$ & 0.058 & $6.67(0.76)$ & $6.27(1.28)$ & 0.106 \\
\hline Q7C & $4.87(1.54)$ & $4.79(1.88)$ & $4.78(1.52)$ & $4.56(1.49)$ & $5.00(1.34)$ & $4.74(1.55)$ & 0.719 & $4.76(1.55)$ & $4.65(1.55)$ & 0.484 \\
\hline Total & $61.0(7.99)$ & $62.7(6.09)$ & $58.5(7.26)$ & $59.3(7.01)$ & $59.7(4.56)$ & $59.9(7.19)$ & 0.084 & $60.63(6.95)$ & $57.29(7.58)$ & 0.005 \\
\hline
\end{tabular}

Mean - mean scale value; SD - standard deviation; K-W - Kruskal-Wallis test; M-W - Mann-Whitney test 


\section{DISCUSSION}

The major findings of this study showed a direct link between a low level of HH knowledge, a high but flawed self-assessment and insufficient, even absent content of information on $\mathrm{HH}$ in general medicine curriculum.

Compliance with $\mathrm{HH}$ among HCWs is usually reported to be very low $(1,14)$. HH adherence is a complex problem affected by appropriateness of $\mathrm{HH}$ knowledge and individual attitudes of HCWs $(8,10,15)$. High risk of infection transmission could be posed also by medical students. It was found that $\mathrm{HH}$ knowledge level decreases with increasing length of the university education $(9,13)$.

A very low level of HH knowledge among medical students has been confirmed, with a risk primarily in the 6th-year students. None of queried year-classes was satisfyingly familiar with hand washing techniques and none but one with disinfectants. At the same time, $72.2 \%$ of students thought they rather followed proper $\mathrm{HH}$ in patient care according to the recommended guidelines and $76 \%$ thought they rather knew recommended guidelines of proper HH. Moreover, more than $60 \%$ considered their behaviour exemplary for their colleagues. This discrepancy could not be ascribed to the fact that medical students are not interested in $\mathrm{HH}$; the perception and attitudes associated with $\mathrm{HH}$ in our respondents were fairly high suggesting that medical students consider $\mathrm{HH}$ useful measure for HAI prevention and $\mathrm{HH}$ non-compliance a risk factor for infection transmission. This was manifested also in strictness of judgment of their colleagues' behaviour: only $53.3 \%$ evaluated their fellows positively (Q4) with the 6th-year students being the most rigorous.

Low HH knowledge level of medical students was repeatedly found $(9,13,15-18)$ and these findings are in accordance with other studies, in which high HH self-assessment on the one hand, and low-level assessment of the fellows' HH compliance on the other hand was confirmed $-81 \%$ vs. $30 \%$ found by Cole (9), and $70-90 \%$ vs. $30-50 \%$ by Pittet et al. (7).

The fact that students have insufficient HH knowledge, but at the same time consider themselves to be adequately educated in this field, may be related either to the acquisition of incorrect patterns and habits observed from HCWs during clinical practice or to a lack of information they are provided with during their university studies.

We suggest that the improper attitudes towards $\mathrm{HH}$ among experienced HCWs could negatively influence students during their clinical training. WHO and HIPAC guidelines reported very low HH compliance among HCWs (7). In 2010, Erasmus et al. reported average compliance values of around 40\% (19) which started to improve after WHO's "Clean care is safer care" initiative, but the rate of $\mathrm{HH}$ adherence and knowledge varies significantly between countries with some specifics for Eastern Europe $(13,20,21)$, often accompanied by flawed self-confidence of HCWs (22). Thus, we cannot rule out the importance of inappropriate examples of $\mathrm{HH}$ compliance provided by hospital stuff during the educational process.

The other side is the educational process itself. A study done in the 3rd-year Slovak medical students showed that almost one third was not able to perform hand washing procedure correctly (23) and the authors concluded that it is necessary to intensify $\mathrm{HH}$ education and practice. However, the analysis of educational content unveiled no occurrence of the fundamental key terms "hand hygiene" or "disinfection of hands" or "procedure of rubbing the disinfectant into hands" in the curriculum documents. When asked (in one part of KQ) to identify the subject which had provided information on the $\mathrm{HH}$, only $1.8 \%$ of students attributed this issue to propaedeutics.

Our results revealed that the $\mathrm{HH}$ topic is incorporated in general medicine curriculum just marginally, and mainly in the preclinical years of the study. Presumably, one concluded that 6th-year students are almost completely familiar with $\mathrm{HH}$ as they have attended clinical-practical training for few years and passed through all the education. However, 6th-year students themselves apparently did not share this opinion of their $\mathrm{HH}$ capabilities, as seen from their low self-evaluation.

We consider the identified shortages in education one of the most crucial factors underlying the detected below-average $\mathrm{HH}$ knowledge level among students and accompanying incorrect habits in $\mathrm{HH}$ procedures. An integral part of $\mathrm{HH}$ improvement in hospital practice, which is world-wide needed, is the preparation of students during education process (24).

$\mathrm{HH}$ education is an essential part of infection control. Through education, it is possible to influence inappropriate patient care practices, thereby contributing to implementation of quality processes. This idea has been supported by studies of educational interventions, where healthcare professionals' HH knowledge improved significantly in schools $(25,26)$.

To our opinion, the basic framework of knowledge should be acquired in preclinical disciplines first, then in preventive medicine, and after all, the acquired knowledge should be used and affirmed during clinical practice trainings. It should be recommended to repeat and train the basic taxonomy of the $\mathrm{HH}$ procedures also in other subjects of the study, thus making possible to form the right attitudes towards $\mathrm{HH}$ compliance within the course of pre-graduate education. Perhaps, multimodal and multidisciplinary HH strategy should be implemented into education programme as reported by various studies $(3,9,27)$. It is necessary to develop a comprehensive $\mathrm{HH}$ strategy, which would be a part of the professional training of all healthcare students, considering also the issue of motivation and the presence of positive or negative examples on $\mathrm{HH}$ during the education in the hospital environment. In this area, the cognitive factors take place $(7,11,17,28,29)$.

\section{Strengths and Limitations of the Study}

A key strength of the present study is that it is the first HHrelated study of its kind in the Slovak Republic. This study, as the pioneering one, analysed the effectiveness of the education in general medicine in relation to $\mathrm{HH}$, and explored the skills and self-assessment, in $\mathrm{HH}$ among medical students. Unique was also the selection of the mixed method approach collecting both quantitative and qualitative data.

The study limitations include conventional sampling process and relatively low number of the completed questionnaires. Low rate of the questionnaires returned by 6th-year students $(28 \%)$ could be due to their absence at the faculty because of their preparations for final examinations. Further research in different settings of educational institutions, clinical practice and/or different healthcare professions is needed to obtain general results 
and perhaps to support our findings by the other phase of research including the method of direct observation.

\section{CONCLUSION}

This study revealed the below-average HH knowledge level and high self-assessment of $\mathrm{HH}$ compliance and attitudes in medical students in relation to the risk of HAI which was probably associated with some shortage in education. HH adherence is a prerequisite for significant reduction of HAIs, while nonadherence poses the risk of contribution to HAI. In this new era of coronavirus risk, $\mathrm{HH}$ adherence among $\mathrm{HCW}$ sains ground more than ever before.

\section{Acknowledgments}

We would like to thank all participants in the research. This research was supported by the Slovak Scientific Grant Agency under grants VEGA 1/0044/18 and VEGA 1/0190/20, the Ministry of Health of the Slovak Republic under the project registration number 2018/20-UKMT-16.

\section{Conflict of Interests}

None declared

\section{Authors' Contributions}

S.K. - conceptualization, methodology, validation, investigation, writing, original draft preparation, reviewing and editing, supervision, project administration; L.M. - investigation, formal analysis, validation, writing, original draft preparation, visualization; N.M. - formal analysis, writing, original draft preparation, visualization; J.K. - writing, original draft preparation, reviewing and editing, formal analysis, validation, visualization; I.T. - validation, writing, original draft preparation, visualization. All authors have read and agreed to the version of the manuscript to be published.

\section{REFERENCES}

1. World Health Organization. WHO Guidelines on hand hygiene in health care: first global patient safety challenge: clean care is safer care. Geneva: WHO; 2009.

2. Freeman MC, Stocks ME, Cumming O, Jeandron A, Higgins JP, Wolf $\mathrm{J}$, et al. Hygiene and health: systematic review of handwashing practices worldwide and update of health effects. Trop Med Int Health. 2014;19(8):906-16.

3. Pittet D, Allegranzi B, Sax H, Dharan S, Pessoa-Silva CL, Donaldson L, et al. Evidence-based model for hand transmission during patient care and the role of improved practices. Lancet Infect Dis. 2006;6(10):641-52.

4. Gould DJ, Moralejo D, Drey N, Chudleigh JH, Taljaard M. Interventions to improve hand hygiene compliance in patient care. Cochrane Database Syst Rev. 2017;9(9):CD005186. doi: 10.1002/14651858.CD005186.pub4.

5. VanDeusen LC, Engle RL, Holmes SK, Parker VA, Petzel RA, Seibert $\mathrm{MN}$, et al. Strengthening organizations to implement evidence-based clinical practices. Health Care Manage Rev. 2010;35(3):235-45.

6. Lo Giudice D, Trimarchi G, La Fauci V, Squeri R, Calimeri S. Hospital infection control and behaviour of operating room staff. Cent Eur J Public Health. 2019;27(4):292-5.

7. Pittet D, Simon A, Hugonnet S, Pessoa-Silva CL, Sauvan V, Perneger TV. Hand hygiene among physicians: performance, beliefs, and perceptions. Ann Intern Med. 2004;141(1):1-8.

8. Suchitra JB, Lakshmi DN. Impact of education on knowledge, attitudes and practices among various categories of health care workers on nosocomial infections. Indian J Med Microbiol. 2007;25(3):181-7.
9. Cole M. Exploring the hand hygiene competence of student nurses: a case of flawed self assessment. Nurse Educ Today. 2009;29(4):380-8.

10. Abdella NM, Tefera MA, Eredie, AE, Lauders TF, Malefia YD, Alene KA. Hand hygiene compliance and associated factors among health care providers in Gondar University Hospital, Gondar, North West Ethiopia. BMC Public Health. 2014;14:96. doi: 10.1186/1471-2458-14-96.

11. Pittet D, Hugonnet S, Harbarth S, Mourouga P, Sauvan V, Touveneau S, et al. Effectiveness of a hospital-wide programme to improve compliance with hand hygiene. Lancet. 2000;356(9238):1307-12.

12. Centers for Disease Control and Prevention. Guideline for hand hygiene in health-care settings. MMWR Morb Mortal Wkly Rep. 2002;25(51):148.

13. Kelcikova S, Skodova Z, Straka S. Effectiveness of hand hygiene education in a basic nursing school curricula. Public Health Nurs. 2012;29(2):152-9.

14. Ajzen I. The theory of planned behavior. Organiz Behav Hum Dec Proces. 1991;50(2):179-211.

15. Shinde MB, Mohite VR. A study to assess knowledge, attitude and practices of five moments of hand hygiene among nursing staff and students at a tertiary care hospital at Karad. Int J Sci Res. 2014;3(2):311-21.

16. Scheithauer S, Haefner H, Schwanz T, Lopez-Gonzalez L, Bank C, Schulze-Röbbecke R, et al. Hand hygiene in medical students: performance, education and knowledge. Int J Hyg Environ Health. 2012;215(5):536-9.

17. Al Kadi A, Salati SA. Hand hygiene practices among medical students. Interdiscip Perspect Infect Dis. 2012;2012:679129. doi: 10.1155/2012/679129.

18. Nobile M, Agodi A, Barchitta M, Brusaferro S, Castaldi S, D'Alessandro $\mathrm{D}$, et al. The effectiveness of educational interventions in university training on hospital hygiene: results of action research. Ann Ig. 2018;30(5 Supple 2):111-20.

19. Erasmus V, Daha TJ, Brug H, Richardus JH, Behrendt MD, Vos MC, et al. Systematic review of studies on compliance with hand hygiene guidelines in hospital care. Infect Control Hosp Epidemiol. 2010;31(3):283-94.

20. Hansen S, Schwab F, Gastmeier P; PROHIBIT study group, Pittet D, Zingg W, et al. Provision and consumption of alcohol-based hand rubs in European Hospitals. Clin Microbiol Infect. 2015;21(12):1047-51.

21. Labrague LJ, McEnroe-Petitte DM, van de Mortel T, Nasirudeen AMA. A systematic review on hand hygiene knowledge and compliance in student nurses. Int Nurs Rev. 2018;65(3):336-48.

22. Kelcikova S, Mazuchova L, Bielena L, Filova L. Flawed self-assessment in hand-hygiene: a major contributor to infections in clinical practice? J Clin Nurs. 2019;28(11-12):2265-75.

23. Novák M, Breznický J, Kompaníková J, Malinovská N, Hudečková H. Impact of hand hygiene knowledge on the hand hygiene compliance. Med Glas (Zenica). 2020;17(1):194-9.

24. Pittet D. Hand hygiene: improved standards and practice for hospital care. Curr Opin Infect Dis. 2003;16(4):327-35.

25. Alemagno SA, Guten SM, Warthman S, Yuong E, Mackay DS. Online learning to improve hand hygiene knowledge and compliance among health care workers. J Contin Educ Nurs. 2010;41(10):463-71.

26. Dos Santos RP, Konkewicz LR, Nagel FM, Lisboa T, Xavier RC, Jacoby $\mathrm{T}$, et al. Changes in hand hygiene compliance after a multimodal intervention and seasonal variation. Am J Infect Control. 2013;41(11):1012-6.

27. D'Allesandro D, Agodi A, Auxilia F, Brusaferro S, Calligaris L, Ferrante $\mathrm{M}$, et al. Prevention of healthcare associated infections: medical and nursing students' knowledge in Italy. Nurse Educ Today. 2014;34(2):191-5.

28. Van De Mortel TF, Kermode S, Progano T, Sansoni J. A comparison of the hand hygiene knowledge, beliefs and practices of Italian nursing and medical students. J Adv Nurs. 2012;68(3):569-79.

29. Bargellini A, Borella P, Ferri P, Ferranti G, Marchesi I. Hand hygiene of medical and nursing students during clinica rotations: a pilot study on knowledge, attitudes and impact on bacterial contamination. Assist Inferm Ric. 2012;31(3):123-30. (In Italian.)

Received September 9, 2020 Accepted in revised form April 19, 2021 